\title{
ATUAÇÃO PROFISSIONAL DO COORDENADOR PEDAGÓGICO E AS IMPLICAÇÕES NO ENSINO E NA APRENDIZAGEM
}

\author{
ATUACIÓN PROFESIONAL DO COORDINADOR PEDAGÓGICO E AS \\ IMPLICAÇÕES NA CALIDAD NO ENSINO E APRENDIZAGEM
}

\author{
PROFESSIONAL ACTION OF THE PEDAGOGICAL ENGINEER AND THE \\ IMPLICATIONS IN QUALITY IN TEACHING AND LEARNING
}

\author{
Rosineide Pereira Mubarack GARCIA ${ }^{1}$ \\ Cind Nascimento SILVA ${ }^{2}$
}

RESUMO: O coordenador pedagógico como um profissional da educação que faz parte da escola possui uma grande relevância no cenário da educação pública brasileira, uma vez que a finalidade da sua atuação é a qualidade do ensino e aprendizagem. Não obstante, o trabalho da coordenação pedagógica tem como referência o Projeto Político Pedagógico da Instituição, que subjaz os princípios da Inclusão, Diversidade, Cidadania e compromisso com o conhecimento socialmente referendado, dialogando com os anseios da comunidade escolar perante a Sociedade. Nesta perspectiva, objetivou-se analisar como suas funções e atribuições se consubstanciam com o desenvolvimento do ofício de seu trabalho e como estas estão pautadas nas principais bases legais educacionais vigentes. Trata-se de uma pesquisa de campo, abordagem qualitativa, a qual envolveu quatorzes coordenadores pedagógicos que atuavam nas escolas públicas de todos os segmentos de ensino, da Educação Infantil, Anos Iniciais e Finais do Ensino Fundamental, do município de Brejões/BA a partir de diálogos com autores como Alonso (2008), Brzezinski (2007), Freire (1982; 1996), Libâneo (2004; 2008), Luck (2007), Gadotti (2003), Vasconcellos (2006), entre outros. Assim sendo, notou-se que a atuação do Coordenador Pedagógico está relacionada intimamente com as funções e atribuições, que por bases legais estão deliberadas, porém essa atuação torna-se comprometida, uma vez que as principais atribuições são secundarizadas, ocorrendo em alguns momentos o desvio de função. Portanto, compreende-se que o papel deste profissional consiste na mediação de saberes e formas de agir que visem mudanças qualitativas no desenvolvimento e aprendizagem, assim como contribuir na constituição de sujeitos cidadãos, a fim de melhorar suas capacidades de ação e competências para viver em sociedade.

PALAVRAS-CHAVE: Coordenador pedagógico. Atuação. Ensino. Aprendizagem.

RESUMEN: El Coordinador Pedagógico como un profesional de la educación que hace parte de la escuela tiene una gran relevancia no hay escenario de la educación pública brasileña, una vez que, una finalidad de su actualización es una calidad del

${ }^{1}$ Universidade Federal do Recôncavo da Bahia (UFRB), Cachoeira - BA - Brasil. Professora do Centro de Ciências Agrárias, Ambientais e Biológicas (CCAAB/UFRB). E-mail: rose.mubarack@gmail.com.

2 Secretaria de Educação do Município, Brejões - Ba - Brasil. Coordenação pedagógica. E-mail: cindnascimento@yahoo.com.br. 
aprendizaje y el aprendizaje. No obstante, el trabajo de coordinación pedagógica tiene como referencia el Proyecto Político Pedagógico de la Institución, que subyace en los principios de Inclusión, Diversidad, Cidadania y compromiso con el conocimiento socialmente referenciado. Esta perspectiva, objetivou-se como se han definido las funciones y las atribuciones se consubstancian con el desarrollo del oficio de su trabajo y como están pautadas en las principales bases legales educacionales vigentes. Trata de una investigación de campo, de la calidad abordable, de la calidad, de la calidad, de los coordinadores pedagógicos que actuaron en las escuelas públicas de todos los segmentos de enseñanza, de la Educación Infantil, de la Anos En la Finanzas del Ensino Fundamental, do município de Brejões / BA a partir De diálogos com autores como Alonso (2008), Brzezinski (2007), Freire (1982, 1996), Libneo (2004, 2008), Luck (2007), Gadotti (2003), Vasconcellos (2006), entre outros. Sin embargo, no se trata de una actuación de un coordinador que esté relacionado intimamente con las funciones y las atribuciones, por lo que las bases legales son deliberadas, Desvio de función Por lo tanto, comprender, hacer, diseñar, diseñar, diseñar, diseñar, diseñar, diseñar, diseñar, diseñar, diseñar, viver en sociedad.

PALABRAS CLAVE: Coordinador pedagógico. Actuação. Ensino. Aprendizagem.

ABSTRACT: The Pedagogical Coordinator as a professional of the education that is part of the school has a great relevance in the scenario of the Brazilian public education, since, the purpose of its performance is the quality of teaching and learning. Nonetheless, the work of pedagogical coordination is based on the Pedagogical Political Project of the Institution, which underlies the principles of Inclusion, Diversity, Citizenship and commitment to socially endorsed knowledge, dialoguing with the yearnings and school community with the Society. In this perspective, the objective was to analyze how their functions and attributions are consubstantiated with the development of the office of their work and how these are based on the main educational legal bases in force. It is a field research, qualitative approach, involving fourteen pedagogical coordinators who worked in public schools in all segments of education, Early Childhood Education, Early Years and Final Years of Elementary School, in the municipality of Brejoes / BA from Of dialogues with authors like Alonso (2008), Brzezinski (2007), Freire (1982, 1996), Libâneo (2004, 2008), Luck (2007), Gadotti (2003), Vasconcellos (2006), among others. Thus, it was noted that the performance of the Pedagogical Coordinator is intimately related to the functions and attributions, which by legal bases are deliberate, but this action becomes compromised, since, the main attributions are secondary, occurring in some moments the function desviation. Therefore, it is understood that the role of this professional is the mediation of knowledge and ways of acting that aim at qualitative changes in development and learning, as well as contributing to the constitution of citizens, in order to improve their capacity for action and skills to Living in society.

KEYWORDS: Pedagogical coordinator. Acting. Teaching. Learning.

\section{Introdução}


Diante de um cenário de mudanças sociais, de novas configurações e exigências de aprendizagem, a realidade educacional contemporânea requer profissionais críticos, multiplicadores e transformadores. Para isto, é necessário também que a escola ingresse na dinâmica atual, que é marcada pela interação e flexibilidade entre os diversos mundos que a cerca.

Educação pública de qualidade é uma busca incessante de muitas instituições de ensino, e para que esta realidade se torne eficaz são necessárias ações que assegurem o trabalho, especialmente o trabalho pedagógico coletivo. Neste sentido, as instituições necessitam de profissionais ainda mais engajados e dinâmicos em prol desta transformação. Partindo deste pressuposto, um dos profissionais que faz parte do processo educacional é o Coordenador Pedagógico; muitas vezes o conceito de coordenação aparece ligado à superioridade, hierarquia, reprodução de práticas e imposição. Daí surge à necessidade de redimensionar sua conceptualização, para que se tenha uma melhor compreensão em torno deste profissional.

Com a intenção de superar essa divisão desigual que caracterizava a escola dos anos 90, século XX, as funções desenvolvidas pelo supervisor escolar e orientador educacional passam a ser desenvolvidas pelo Coordenador Pedagógico; este, por sua vez, passa a assumir uma postura diferente, e ao contrário de impor, viabiliza uma relação dialógica com todos os segmentos da escola, especialmente com a equipe docente.

Neste contexto, o trabalho do coordenador pedagógico é de grande valia, pois está intimamente relacionado com os processos pedagógicos que refletem automaticamente na qualidade do ensino e aprendizagem e propicia também a mediação de uma educação para o desenvolvimento social, político, cultural, que conceda um espaço de emancipação, ultrapassando a dimensão educacional como mera transmissora de conteúdos, conforme aponta Freire (1996), que não se limite a transferir conhecimentos, mas, sobretudo, permita a construção do conhecimento e a convicção de que a mudança é possível.

Deste modo, este trabalho busca refletir sobre a importância da atuação profissional do coordenador pedagógico, considerando a sua pertinência enquanto gestor dos processos pedagógicos que refletem significativamente nas mudanças que são indispensáveis para a qualidade do ensino e aprendizagem.

A pesquisa contou com uma abordagem qualitativa do tipo exploratória a partir da pesquisa de campo, na qual envolveu quatorzes coordenadores pedagógicos que 
atuavam nas escolas públicas de todos os segmentos de ensino, da Educação Infantil, Anos Iniciais e Finais do Ensino Fundamental, do município de Brejões 3 /BA. Foram utilizados os procedimentos para coleta de dados, questionário semiestruturado, análise documental do campo investigado.

O artigo está estruturado em quatro seções, sendo que a primeira visa contemplar a apresentação geral da pesquisa, seu objetivo e metodologia. A segunda destina-se às discussões a cerca das funções, atribuições e importância do trabalho do coordenador pedagógico e suas dimensões diante da escola a partir de diálogos com autores como Alonso (2008), Brzezinski (2007), Freire (1982; 1996), Libâneo (2004; 2008), Luck (2007), Gadotti (2003), Vasconcellos (2006), entre outros. A terceira destina-se ao delineamento das funções e atribuições deste profissionais a partir das principais bases legais que regem a educação. Já o quinto capítulo refere-se aos dados coletados no campo empírico e a tessitura de possíveis análises.

\section{Atuação do coordenador pedagógico na escola}

$\mathrm{O}$ coordenador pedagógico como um dos agentes que fomenta e articula o funcionamento da escola, fazendo parte da gestão pedagógica, também comunga de todas as construções das ações, do mesmo modo em que age enquanto prática educativa. Um dos grandes aspectos das organizações escolares relevantes para a prática da gestão da escola diz respeito à questão organizacional ou cultura da escola; esta, por sua vez, torna-se importante na medida em que se percebe a escola como um espaço de construção e reconstrução da cultura, não somente a produção de cultura científica, mas social e humana. Esta cultura, segundo Libâneo (2008), corresponde:

Àqueles significados, modos de pensar e agir, valores, comportamentos, modos de funcionamento que, de certa forma, mostram a identidade, os traços característicos, da escola e das pessoas que nela trabalham. A cultura da escola (ou cultura organizacional) é o que sintetiza os sentidos que as pessoas dão às

${ }^{3}$ Brejões fica localizada no Recôncavo da Bahia, fazendo divisa com os municípios de Ubaíra, Milagres, Nova Itarana, Santa Inês, e Amargosa. Foi fundada por volta de 1880, através da passagem dos nordestinos Estevão Chaves e João Guerra na margem esquerda do rio Brejões, que perceberam a fertilidade do vale e a abundância da água e a partir disso resolveram erguer casa para residência e assim iniciaram o plantio do café. Perseguidos pelas secas do Nordeste, muitos grupos de retirantes passavam, os quais influenciados pelos primeiros moradores ali ficavam e assim iniciou-se o povoamento da região. De acordo com o censo do IBGE (2010), a população brejoense é constituída por 14.282 habitantes e uma economia basicamente agrícola e pecuária, com forte produção de café. No contexto educacional possui 13 Instituições entre estaduais e municipais, compreendidas entre pré-escola, ensino fundamental I e II e ensino médio com cerca de 3.440 alunos matriculados. (IBGE, 2010) 
coisas, gerando um padrão coletivo de pensar e perceber as coisas e de agir. (p. 33).

Deste modo, a escola pode ser caracterizada como um espaço de construção coletiva, no qual professores, coordenadores pedagógicos, gestores, merendeiras, porteiros e demais funcionários compartilham de um mesmo objetivo, que significa propor uma educação de qualidade, que fomente a formação crítica, reflexiva e cidadã dos alunos.

O coordenador pedagógico, por ser um dos agentes e por desempenhar também um trabalho junto aos professores, pode propor através da sua atuação a maior participação dos mesmos nas questões relacionadas à organização e gestão da escola, pois essa abertura permite a todos os envolvidos a responsabilidade coletiva pela escola, e não somente isto, mas proporciona o desenvolvimento de sua profissionalidade, uma vez que os professores também aprendem quando compartilham seus anseios, seu contexto de trabalho, ou seja, sua profissão. A partir desta reflexão, compreende-se que a construção e consolidação do trabalho docente na prática trás para o interior da escola à formação continuada desses profissionais, uma vez que esta necessita ser uma "formação mobilizadora, concreta, ampla e afinada no processo permanente de reflexão" (SILVA; SILVA, 2016, p. 43). É válido salientar que a construção profissional do professor reflete em uma boa forma de organização do trabalho escolar como um todo. Segundo Libâneo (2008):

Depende de uma boa estrutura de coordenação pedagógica que faça funcionar uma escola de qualidade, propondo e gerindo o projeto pedagógico, articulando o trabalho de vários profissionais, liberando e favorecendo a constante reflexão na prática e sobre a prática (p. 41).

Assim sendo, o desenvolvimento da escola e a conquista por uma educação de qualidade diz respeito também à união de coordenadores pedagógicos e professores, uma vez que estes assumem de maneira coletiva a gestão do cotidiano da escola, integrando em um só objetivo as questões que envolvem o projeto pedagógico, o processo de ensino e aprendizagem, o sistema de gestão, a avaliação, ou seja, a escola como um todo. A relação deste profissional para com a equipe de professores tem como principal atribuição a assistência didática pedagógica, refletindo sobre as práticas de ensino e possibilitando novas situações de aprendizagem: tais situações devem ser capazes de auxiliar os alunos ao longo da sua formação. 
Este profissional precisa ainda agir como um mediador, capaz de propor a significação e ressignificação da ação pedagógica, levando em consideração também que a construção do Projeto Político Pedagógico deve ser uma articulação coletiva, na opinião de Vasconcellos (2006):

A coordenação pedagógica é a articuladora do Projeto Político Pedagógico da instituição no campo pedagógico, organizando a reflexão, a participação e os meios para a concretização do mesmo, de tal forma que a escola possa cumprir sua tarefa de propiciar que todos os alunos aprendam e se desenvolvam como seres humanos plenos, partindo do pressuposto de que todos têm direito e são capazes de aprender. (p. 87).

O coordenador é o profissional que responde pela viabilização, integração e articulação do trabalho pedagógico, sendo diretamente relacionado com diversas relações, as quais devem ir de encontro aos aspectos de colaboração. Pois, essa relação se faz necessária na medida em que também se compreende que este sujeito não atua sozinho, ele protagoniza com os demais (família, alunos, funcionários, gestão, conselho escolar, professores), propiciando o sentido e a importância do trabalho coletivo e colaborativo.

A postura de liderança não é uma característica exclusiva de diretores e coordenadores pedagógicos, sendo ela possível de ser desenvolvida por todas as pessoas, por meio de práticas que acenem para o desenvolvimento profissional e humano. Visto que as práticas de participação nos processos da gestão da escola, por si só, não dão conta das ações necessárias para que seja efetivada a qualidade de ensino, esta é um meio de melhor alcançar democraticamente os objetivos da escola, que se centram na qualidade dos processos de ensino e aprendizagem.

Para que haja a consolidação desse movimento relacional e democrático na escola, é necessário um planejamento que vise à consciência colaborativa, possibilitando o entendimento de que a escola é um espaço complexo e sua qualidade depende da participação de todos. Assim sendo,

Realizar os diversos planos e planejamentos educacionais e escolares, organizando a educação, significa exercer uma atividade engajada, intencional, científica, de caráter político e ideológico e isento de neutralidade. Dessa forma, planejar, em sentido amplo, é um processo que visa dar respostas a um problema, estabelecendo fins e meios que apontem para sua superação, de modo a atingir objetivos antes previstos, pensando e prevendo necessariamente o futuro, mas sem desconsiderar as condições do presente e as experiências do passado, levando em conta os contextos e os pressupostos filosófico, cultural, 
econômico e político de quem planeja e de com quem se planeja. (GADOTTI, 2003, p. 63).

Desta forma, a escola ganha quando estes aspectos são levados em consideração e o coordenador pedagógico necessita promover práticas que acenem para fazer conjunto, além de ser necessário que "quando se pensar em algum setor da escola, devese pensar em suas relações com os demais setores, bem como a comunidade" (LUCK, 2007, p. 10), refletindo desta forma em um espaço que é múltiplo, mas também dialógico e participativo.

Ainda assim, o trabalho da coordenação pedagógica necessita proporcionar uma relação aberta e dinâmica entre os pares, compreendendo que a interdisciplinaridade e o envolvimento com o outro é o ponto crucial para desencadear não só a qualidade na sua atuação, mas no âmbito educacional como um todo. Libâneo (1996) afirma que:

Quem ocupa cargo de liderança como diretor ou coordenador pedagógico precisa despor-se do posicionamento de predominante autocrático para possibilitar o desenvolvimento de um clima em que todos contribuam com ideias, críticas, encaminhamentos, pois a gestão e participação pedagógica pressupõem uma educação democrática (p. 200).

Ou seja, este cargo envolve muito mais as dimensões da escuta, da partilha, visando à valorização das ações coletivas, ações essas que devem estar vinculadas ao eixo pedagógico desenvolvido na instituição. Do mesmo modo que também assume uma postura de mediador, pois além de prestar subsídios pedagógicos aos docentes ele precisa cultivar um relacionamento afetuoso com os alunos, pais e comunidade a qual está interagindo diariamente com a escola. Todavia, "a finalidade da coordenação não é somente o desenvolvimento do conhecimento, mas também o despertar de capacidades reflexivas e o repensar de atitudes, proporcionando uma prática de ensino mais comprometida, autêntica e eficaz". (SILVA, 2015, p. 26).

De todo modo, o aparato central da coordenação pedagógica "são todos os processos de aprendizagem onde quer que ocorram" (VASCONCELLOS, 2006, p. 90). Aponta-se a grande relevância do coordenador pedagógico na gestão dos processos pedagógicos e escolares, não somente no contexto individual, mas, sobretudo, coletivo, fomentado a articulação escola-comunidade e exercendo o trabalho de formação que permite através desta prática educativa e transformadora repensar não só a dinâmica e clima institucional da escola, mas o cenário da educação como um todo e sua prática deve está implicada no combate a tudo que desumaniza a escola. 
Ainda assim, existem grandes implicações no que concerne às funções e atribuições do coordenador que necessitam ser discutidas, haja vista que estas se misturam no cotidiano da escola, muitas vezes, devido à falta de conhecimento tanto por parte deste profissional, da escola e da sociedade.

Nesta perspectiva, o coordenador, por diversas razões, está imerso em um emaranhado de atribuições, no entanto, há um eixo especial ao qual este profissional deve se ater, que é a relação com os professores, seja para propor formação continuada ou para auxiliar práticas pedagógicas que possibilitem melhores resultados no ensino e aprendizagem. Desta forma, o trabalho do coordenador promove a tomada de consciência dos professores em suas ações e possibilita o conhecimento do espaço em que atuam, assim como "ele exerce o papel de articulador do processo de ensinoaprendizagem da escola, incluindo a formação continuada docente". (GEGLIO, 2005, p. 116).

Ressalta-se que este processo contínuo consiste também na mediação de saberes e formas de agir que visem mudanças qualitativas no desenvolvimento e aprendizagem dos alunos, ajudando-os a se constituírem enquanto sujeitos cidadãos, a fim de melhorarem sua capacidade de ação e competências para viver em sociedade.

Vasconcellos (2006) aponta que o aparato principal de atribuição e função que reflete a atuação do coordenador deverá estar ligado diretamente com a formação dos professores, com práticas pedagógicas que viabilizem o ensino-aprendizagem de qualidade, e com o projeto político pedagógico da instituição.

Sendo assim, espera-se que atuação do coordenador pedagógico integre o exercício do trabalho crítico, reflexivo, avaliativo de si e do próximo, na qual acene o saber-fazer coletivo, respeitando as especificidades postas por cada setor da escola. É válido salientar que este sujeito não surge como uma solução para sanar todos os desafios da escola, mas como um profissional a mais para somar-se à equipe gestora a fim de fazer frente aos desafios da escola na atualidade.

\section{O coordenador pedagógico à luz das bases legais}

O coordenador pedagógico existe desde o século XIX, porém com outra dimensão. Pires (2005) e Horta (2007) apontam a origem da função (anteriormente supervisor educacional) desde o início da educação jesuíta no Brasil, porém apresentam como marco inicial a década de setenta do século XX, pois optou-se por quando surgem 
as primeiras necessidades de haver um especialista que estivesse na escola junto aos docentes para contribuir nas práticas pedagógicas.

Nesta perspectiva, o cenário educacional, naquele período, estabelece os especialistas em educação como orientadores. Tal afirmação se consolida com a primeira Lei de Diretrizes e Bases da Educação Nacional - LDBN nº 4.024, de 20 de dezembro de 1961, que definiu a função dos demais especialistas de educação como orientadores de educação.

No que diz respeito à Lei 5692/71, de 11 de agosto de 1971 que dispõe acerca das diretrizes e bases para o ensino de $1^{\circ}$ a $2^{\circ}$ graus e outras providências, aponta em seu Art. 33 que: “A formação de administradores, planejadores, orientadores, inspetores, supervisores e demais especialistas de educação será feita em curso superior de graduação, com duração plena ou curta, ou de pós-graduação” (BRASIL, 1971). Ainda de acordo com a legislação citada, as funções do supervisor escolar dizem respeito ao "planejamento; coordenação e avaliação do currículo; assessoramento da administração escolar; orientação a respeito da atuação dos docentes em sala de aula e avaliação do currículo em relação ao desempenho dos alunos" (BRASIL, 1971). Todavia, nota-se que tanto a formação quanto as funções dos especialistas educacionais passam após esta legislação por uma perspectiva ainda mais direcionada.

Um marco histórico e significativo no processo educacional, o qual ajudará a compreender o processo dos entraves do papel do orientador educacional, se deu no Governo Militar de 1964, que trouxe a centralização de poderes ostentados pelo Governo Federal nas mãos do Presidente da República e dos órgãos centrais, abolindo a autonomia dos estados e municípios.

Neste cenário político emergem mudanças nas políticas públicas educacionais, dentre elas, as reformas dos sistemas escolares e a reconfiguração dos cursos de formação de professores e outros profissionais da educação. Tais reformas foram feitas através da Lei $N^{0} 5.692 / 71$ que, ao tratar de formação docente, delibera a divisão do Curso de Pedagogia. Apesar da existência da fragmentação do trabalho, a Lei trouxe pontos relevantes, como a descentralização do ensino e a flexibilização dos currículos, que propiciaram mudanças significativas para a educação como um todo.

Com o surgimento da nova ordem, bem como as modificações políticas que marcaram os anos 1980 e 1990 do século XX, era preciso, no Brasil, uma transformação na escola, para que esta tivesse a capacidade de atender a nova ordem política e social 
que estava sendo vivida naquele momento. Com a retomada da democracia e a descentralização do poder, várias situações (principalmente no âmbito educacional) foram modificadas, a volta da autonomia universitária e a gestão democrática nas escolas públicas foram sinais desse processo. Neste sentido, é possível considerar que a Constituição de 1988 demarca significativas reformas para se pensar o contexto da Educação no Brasil, valendo atentar para os direitos fundamentais do cidadão no que cerne à educação.

A partir da conjuntura social estabelecida após a Constituição Federal de 1988, que instaura o regime político democrático no Brasil, todas as leis passam a ser adequadas a essa nova estrutura, que desencadeou profundas mudanças políticas, econômicas e sociais. A Educação passa a sofrer grandes alterações para ajustar-se a esse novo cenário social. Com base nesse novo contexto, um conjunto de reformas foi implantado no sistema educacional, as quais provocaram a reestruturação do ensino no Brasil, os seus aspectos relativos à organização escolar, à gestão, ao currículo, entre outros. As alterações na legislação educacional brasileira comungaram essa nova reconfiguração, tendo como ponto principal a deliberação da Lei de Diretrizes e Bases da Educação Nacional, de N 9.394, de 20 de dezembro de 1996.

O que se instaura nas escolas é uma concepção de gestão democrática que pense sua organização enquanto processo coletivo, e neste processo de coletividade a organização pedagógica da escola necessita ser vista a partir do eixo central, que é fomentar práticas pedagógicas que acenem para a qualidade do ensino público. Pode-se ainda afirmar que a gestão democrática seja a junção da Direção com a coordenação pedagógica, ao tempo em que estes gestores possam viabilizar a troca de experiências entre os pares da escola.

Especificamente no estado da Bahia, o coordenador pedagógico surge no ano de 1997, através da Lei Estadual $n^{\circ}$ 7.023, de 23 de Janeiro de 1997, regulamentada pelo Decreto $\mathrm{n}^{\circ}$ 6.741, de 01 de Junho de 1997, que oficializou o Coordenador como profissional da escola. Nos termos dessa Lei, lê-se, no $\operatorname{Art}^{\circ} 7$ :

Os atuais cargos de Orientador Educacional e Supervisor Escolar, da estrutura do Magistério de $1^{\circ}$ e $2^{\circ}$ graus do Estado, mantidos os correspondentes quantitativos em cargos de Coordenador Pedagógico, cujas especificações abrangerão as atribuições das nomenclaturas ora transformadas, passando as mesmas a serem desempenhadas pelos ocupantes do cargo citado, de acordo com as necessidades dos estabelecimentos de ensino em que sejam lotados (BAHIA, 2002, p. 2). 
A Lei de $\mathrm{n}^{\circ}$ 8.261, de 29 de maio de 2002, dispõe do Estatuto do Magistério Público do Estado da Bahia e consolida a Legislação do Magistério de 1975 a 2002, ajustando-as às Constituições Federal e Estadual e à Lei de Diretrizes e Bases da Educação Nacional, sancionada pelo então governador Otton Alencar. As deliberações do documento dizem respeito a todas as dimensões dos profissionais que atuam na escola pública, de acordo com o Art.4: "Compõem o Magistério Público Estadual do Ensino Fundamental e Médio os servidores que exerçam atividades de docência e de suporte pedagógico direto à docência, incluídas as de direção, planejamento, administração escolar e coordenação pedagógica" (BAHIA, 2002, p. 2). Ainda assim, o Art. $6^{\circ}$ se refere ao quadro de profissionais do Magistério, ou seja, afirma que "compõese dos seguintes cargos escalonados: I - Professor - P; II - Coordenador Pedagógico CP” (BAHIA, 2002, p. 2).

Contudo, a legislação que regulamenta as funções e as atribuições do coordenador pedagógico descreve com objetividade o que cabe a esse profissional da educação, representando um avanço enquanto política pública educacional, entretanto, é necessário refletir em que medida os estados e municípios compreendem a efetividade dessas políticas e como a implementam.

\section{O que dizem os coordenadores pedagógicos do município de Brejões/BA}

A pesquisa contou com a colaboração dos coordenadores no âmbito das Escolas Públicas de todos os segmentos de ensino (Ed. Infantil, anos iniciais e finais do Ensino Fundamental), a qual buscou analisar como as funções e atribuições destinadas a este profissional têm sido desenvolvidas no cotidiano escolar e como estas corroboram para sua atuação profissional, considerando a sua relevância para o processo da qualidade educacional.

Neste sentido, há uma grande importância em compreender o cenário que compõe tanto as atribuições quanto as funções do coordenador, desde as bases legais até o que é desenvolvido no interior da escola, uma vez que estas refletem significativamente no desenvolvimento da sua atuação. Sobre estas questões, os dados apresentados a seguir, construídos a partir de questionário semiestruturado, sintetizam os significados que estes sujeitos deram a esses pilares a partir das atividades desenvolvidas por eles no cotidiano da escola. 
Gráfico 1: Atividade que desempenha na escola

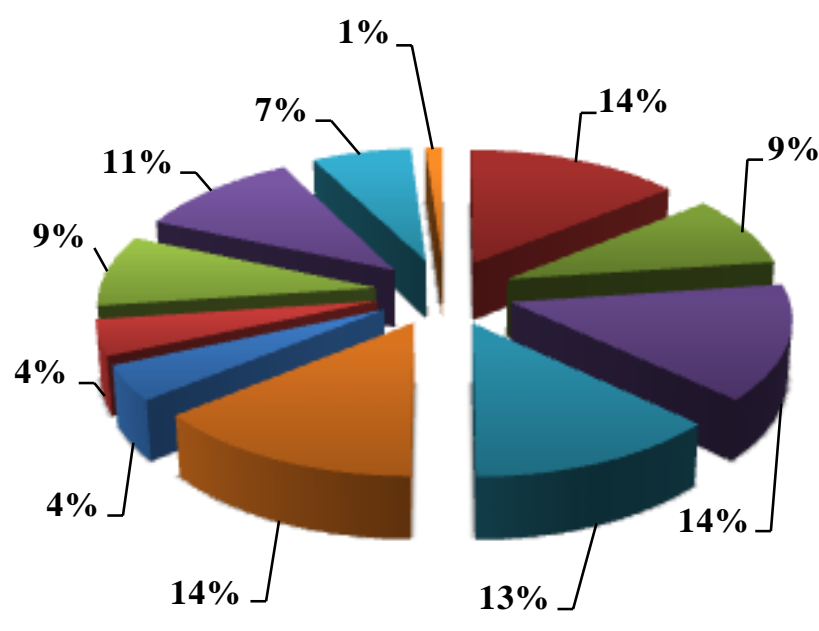

- Auxilia na construção do cardápio escolar

- Media a construção do Projeto Político Pedagógico

- Resolve e contribui nas demandas administrativas junto a gestão da Escola

- Fomenta práticas pedagógicas que auxiliam na atuação do professor em sala de aula

- Constrói mecanismos de metodologias para proporcionar o ensino e a aprendizagem

- Planeja e Coordena ações pedagógicas.

Propõe atividades formativas para todo corpo da escola.

- Substitui o Gestor quando este não se faz presente

- Articula estudos e propostas que ajuda para o desenvolvimento do sistema, rede de ensino e da escola.

- Avalia a aprendizagem do aluno.

- Substitui o professor quando este falta por alguma eventualidade

Outros

Fonte: Elaboração própria.

De acordo com o gráfico acima é possível afirmar que nenhum dos sujeitos marcou a alternativa $\mathrm{A}$, treze marcaram a $\mathrm{B}$, oito a $\mathrm{C}$, treze a $\mathrm{D}$, doze a $\mathrm{E}$, treze a $\mathrm{F}$, quatro a $\mathrm{G}$, quatro a $\mathrm{H}$, oito a $\mathrm{I}$, dez a $\mathrm{J}$, seis a $\mathrm{K}$ e, por fim, um marcou a alternativa outros, especificando: “Junto com a professora monitora do 'Mais Educação' estudamos e desenvolvemos proposta de trabalho para a oficina de Acompanhamento Pedagógico." (sic) (CP 9).

Percebe-se que as alternativas $\mathrm{B}, \mathrm{D}, \mathrm{E}$ e $\mathrm{J}$ foram as que tiveram maior ênfase para os sujeitos. Sobre a questão B é possível afirmar de acordo com Vasconcellos (2006) que coordenação é:

[...] articuladora do Projeto Politico Pedagógico da instituição do campo pedagógico, organizando a reflexão, a participação e os meios para a concretização do mesmo, de tal forma que a escola possa cumprir sua tarefa de propiciar que todos alunos aprendam e se desenvolvam como seres humanos plenos, partindo do pressuposto de que todos têm direito e são capazes de aprender (p. 87).

Ainda assim, é necessário compreender que o Projeto Político Pedagógico não se constitui em longas páginas de objetivos, mas em um documento que pontue fatores que sejam definidos e assumidos pelo conjunto da escola. Fusari (2000) e Garrido (2000) 
concebem que o trabalho da coordenação deve ser sempre articulado ao Projeto Político Pedagógico, pois possibilita ao professor a reflexão sobre a sua ação e sobre o espaço em que trabalha, assim como favorece ao coordenador o repensar sobre sua atuação.

Com base na questão: Existem funções desenvolvidas por você, nas quais considera fora de suas atribuições? Caso afirmativo, especifique-as. Os coordenadores pontuaram:

CP 1 Sim, sempre que é preciso ajudo nas questões administrativas e financeiras mesmo sabendo que não é minha atribuição, mas gosto de ajudar.

CP 2. Não.

CP 3. Porteiro, quando este falta, digitador, gestor, secretário, professor, auxiliar de classe quando estes faltam ou chegam atrasados. CP 4. Sim. Controlar e resolver questões de indisciplina nas aulas e consequentemente na escola.

CP 5. Sim. Fazer o controle dos alunos indisciplinados no decorrer das aulas.

CP 6. Não.

CP 7. Sim. No entanto, não são ações constantes mais acontecem tais como: digitação, decoração de eventos.

CP 8. Sim. Digitar atividades, fazer matrícula bem como outras demandas administrativas, armar data show para professores.

CP 9. Não.

CP 10. Substituição de professor (a).

CP 11, Sim. Substituição de professores.

CP 12. Há algumas questões que sei que não são atribuídas ao coordenador, como organizar eventos da escola, desde a elaboração de convites à ornamentação do mesmo.

CP13. Atuamos em uma área designada à educação. Dificilmente no ambiente escolar nós desenvolvemos apenas o que é nossa função. Estamos sempre trabalhando em equipe e a gestão está atrelada também ao ped. (sic) (2015).

De acordo com a resposta do CP3 (três), nota-se que uma das grandes questões que se apresenta na contemporaneidade é a falta de entendimento do espaço de atuação da coordenação, que em muitas vezes, tanto a escola quanto o próprio profissional não dá conta de compreender. Neste sentido, a partir de todas as respostas é possível afirmar com base em Vasconcellos (2006) que existe uma "definição negativa do papel”, ou seja, aquilo que coordenador não é ou não deveria ser:

Não é fiscal, não é dedo-duro (que entrega os professores para a direção ou mantenedora), não é pombo correio (que leva recado da direção para professores e dos professores para a direção), não é coringa/tarefeiro/quebra galho/salva-vidas (ajudante de direção, auxiliar de secretária, enfermeiro, assistente social, etc), não é tapa buraco (que fica "toureando" os alunos em sala de aula no casa de falta de professor) não é burocrata (que fica às voltas com relatórios e mais relatórios, gráficos, estatísticas sem sentido, mandando um 
monte de papel para os professores preencherem - escola de "papel"), não é gabinete (que está longe da prática e dos desafios efetivos dos educadores)m não é diciário (que tem dicas e soluções para todos os problemas, uma espécie de fonte inesgotável de técnicas, receitas), não é generalista (que entende quase nada de quase tudo) (p. 87).

Todavia, este profissional possui suas funções e atribuições, que devem ser muito bem definidas pelo coletivo da escola, para que não haja desvios de funções que acarretem uma atuação desqualificada, sendo que, em grande medida, "o cotidiano do coordenador pedagógico ou pedagógico-educacional é marcado por experiências e eventos que levam, com frequência, a uma atuação desordenada, ansiosa, imediatista e reacional, às vezes até frenética" (PLACCO, 2003, p. 47).

No que diz respeito às questões $\mathrm{D}$ e E é importante salientar que o coordenador fomenta a qualidade dos mecanismos de ensino e aprendizagem, quando estas são construídas em comunhão com o professor. Esse processo de construção depende em certa medida do entendimento que a equipe possui com relação ao contexto real da escola, de seus objetivos, anseios, metas, sobretudo da concepção de Educação que a instituição defende, uma vez que estas ações decorrem de um projeto construído coletivamente e, por isto, não devem ser desarticulados das práticas desenvolvidas na sala de aula. Neste sentido, "as possibilidades de contribuição do coordenador pedagógico estão situadas num espaço em que o refletir-junto e o construir-junto precisam ser aprendidos e vivenciados por toda a equipe” (BRUNO, 2012, p. 107).

Assim, de acordo com a estrutura organizacional da educação, construída historicamente, as funções e atribuições destinadas ao coordenador pedagógico devem ser estruturadas com base na legislação majoritária, sendo a Lei de Diretrizes e Bases da Educação Nacional (LDBEN/1996), depois a lei estadual, em se tratando da Bahia, o Estatuto do Magistério, e por fim o Regimento Municipal. Os primeiros documentos citados sinalizam muitos aspectos, porém, cabe às secretarias de educação (através do regimento municipal), principalmente por compreender melhor a dinâmica do cenário real da educação no lugar em que se encontra, traçando o efetivo papel deste profissional na escola. Sobre esta questão, o gráfico a seguir apresenta as respostas dos sujeitos sobre o conhecimento que eles possuem sobre os documentos legais que regem a coordenação: 
Gráfico 2: Documentos Legais que possuem conhecimento sobre as atribuições do Coordenador Pedagógico

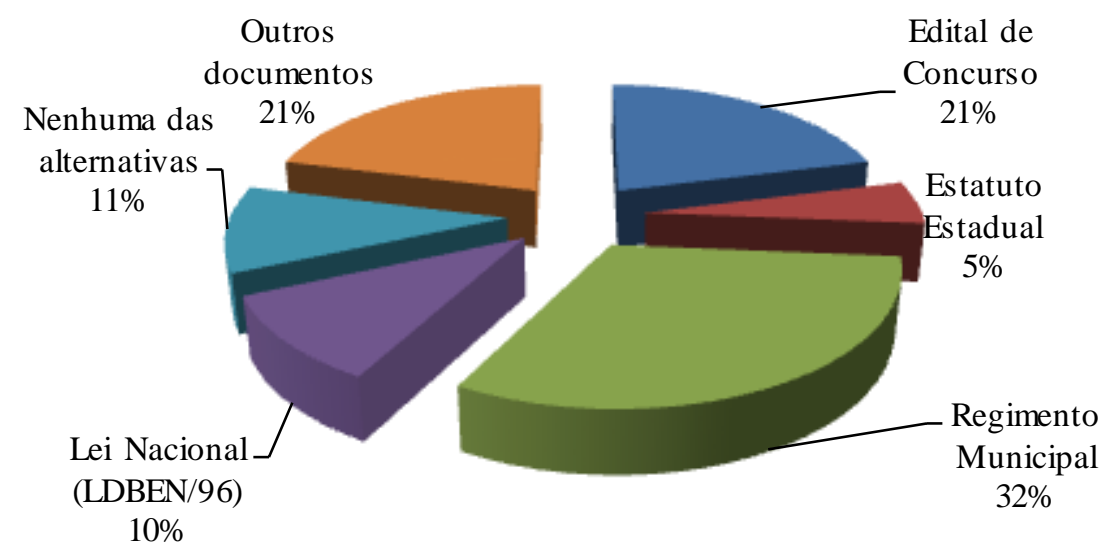

Fonte: Elaboração própria.

Entre os mais citados estão o Edital de concurso do município de Brejões, o Regulamento Municipal, e os outros documentos apontados por eles, que foram: "Plano de Carreira do Magistério", "Artigos", "Plano de Carreira do Magistério", "Documentos escolares (PPP/Regimentos)". O Estatuto Estadual e a LDBEN/96 tiveram pouca ênfase, e apenas dois sujeitos afirmaram nenhuma alterativa.

É válido salientar que o último edital do concurso público do município de Brejões, publicado a partir do Decreto de $\mathrm{n}^{\circ}$ 105, de 10 de Novembro de 2006, abrange, para a área da Educação, vagas a serem preenchidas apenas para professores de nível I: não faz menção a qualquer aspecto que seja destinado aos Coordenadores Pedagógicos.

A função da coordenação, segundo Medina (1995), consiste na ação docente, cujo acompanhamento vise à aprendizagem do aluno. Destaca que o papel do Coordenador Pedagógico necessita ser como o de "conceber-se como um sujeito que produz, reproduz e pesquisa diferentes maneiras de ensinar, de aprender e de orientar" (p. 155); o autor ainda ressalta que o trabalho da coordenação é significativo para a escola, pois "envolve a ação de professores, o anseio da comunidade e o desejo dos alunos" (p. 158).

Alonso (2008) entende o coordenador como um articulador da reconstrução do currículo escolar, na medida em que este consiga abarcar os desafios da aprendizagem dos alunos, visando também as práticas de coordenação com o "desenvolvimento de clima de camaradagem e cooperação e valorização das experiências vividas em sala de aula pelos educadores" (p. 176). 
Sobre as funções e atribuições, o coordenador corresponde à gestão de processos e práticas que vão desde as políticas educacionais das instituições, entendidas no seu Projeto Político Pedagógico, até a gestão de situações que surgem do cotidiano do trabalho pedagógico e do coletivo docente. Para isto, é necessário um coordenador reflexivo, que compreenda que a reflexão ocorre da e na prática, implicando um projeto educativo que esteja pautado pela coletividade e não por ações distantes que não correspondem aos anseios coletivos da escola. Portanto, o coordenador pedagógico ocupa um espaço preponderante na instituição escolar, uma vez que seu elo principal se consolida no trabalho pedagógico.

Diante disto, vale ainda ressaltar que o coordenador está constantemente em processo de formação, tanto profissional quanto humana. Sendo assim, tão importante quanto a atenção para os docentes e discentes, é a atenção para o coordenador, atenção esta que deve ser da escola, da sociedade, das políticas educacionais, em apoio à função e reconhecimento de seu trabalho.

\section{Considerações finais}

O coordenador pedagógico é um profissional recente no contexto da educação pública brasileira. Seu percurso decorre de muitos avanços: este anteriormente possuía a função de vigiar o trabalho do professor, porém nos dias atuais possui a função de mediar, contribuir para o trabalho da instituição, fomentar o diálogo contínuo entre seus pares, visando qualidade nos processos de ensino e aprendizagem, confirmando que sua atuação não se limita apenas às questões burocráticas, mas trás no bojo da sua atuação a gestão pedagógica e a formação cidadã.

Outro aspecto fundamental é a existência das bases legais que dão sentido à coordenação pedagógica, ao passo que também permite a percepção do campo de sua atuação, assim como reflete sobre a necessidade de observar as funções e atribuições destinadas a estes no exercício de sua profissão, uma vez que estas, sendo bem definidas, não corroboram para a secundarização de suas funções, e, portanto, não acarretam num comprometimento na gestão pedagógica.

Dessa maneira, o trabalho da coordenação pedagógica necessita refletir para o desenvolvimento de uma educação humanizadora e política, a fim de possibilitar a todos os sujeitos formação crítica e reflexiva. Sua atuação não pode ser desvinculada do sentido de problematizar, instigar, refletir, priorizando sempre a condição de uma 
consciência que permita que a Educação transcenda, além de que cabe a este profissional o exercício de um papel que contribua sobremaneira para o avanço da escola pública.

\section{REFERÊNCIAS}

ALONSO, M. A supervisão e o desenvolvimento profissional do professor. In: São Paulo, n. 192, maio 2008. Disponível em:

<http://revistaescola.abril.com.br/edicoes/0192/>. Acessado em: 29 ago. 2014.

BRASIL. Lei 5.962, de 11 de agosto de 1971. Disponível em:

<http://www.planalto.gov.br/ccivil_03/Leis/L5692.htm>. Acesso em: 23 jan. 2015.

BRASIL. Constituição da República Federativa do Brasil. Texto constitucional promulgado em 5 de outubro de 1988, com alterações adotadas pelas Emendas Constitucionais $n^{\circ} 1 / 92$ e 31/2000 e pelas Emendas Constitucionais de Revisão n. 1 a 6/94. Brasília: Senado Federal: 2001.

BRASIL. Lei 4.024, de 20 de dezembro de 1961. Disponível em: <http://www.senadofederal.gov.br/legislação/listapublicações.html>. Acesso em: 25 jan. 2015.

BRASIL. Ministério da Educação. Conselho Nacional de Educação. Resolução CNE/CP n' 1, de 15 de maio de 2006. Institui as Diretrizes Curriculares Nacionais para 15 Curso de Graduação em Pedagogia, licenciatura.

BAHIA, Secretaria da Educação. Legislação básica do magistério público estadual de Ensino Fundamental e médio: Estatuto - regulamento e plano de carreira. Salvador, Lei $n^{\circ} 7.023$ de 23/01/1997 e Decreto nº 6.471 de 01/06/1997.

BAHIA. Lei no 8.261, de 29 de maio de 2002. Dispõe sobre o Estatuto do Magistério Público do Ensino Fundamental e Médio do Estado da Bahia.

BRZEZINSKI, I. Pedagogia, pedagogos e formação de professores: busca e movimento. Campinas, SP: Papirus, 2007.

BRUNO, E. B. G. Desejo e condições para mudança no cotidiano de uma coordenadora pedagógica. In: PLACCO, V. M. N. S.; ALMEIDA, L. R. (orgs.). O Coordenador pedagógico e o cotidiano da escola. 3. ed. São Paulo, Loyola, 2005.

FREIRE, Paulo. Educação: sonho possível. In: BRANDÃO, C. R. (org). O educador: vida e morte. 2 ed. Rio de Janeiro: Graal, 1982

FREIRE, Paulo. Pedagogia da autonomia: saberes necessários à prática educativa. São Paulo: Paz e Terra, 1996. 
GADOTTI, Moacir. Educação e poder: introdução à pedagogia do conflito. São Paulo: Cortez, 1980.

GARRIDO, E. Espaço de formação continuada para o professor-coordenador. In: BRUNO, E. B. G.; ALMEIDA, L. R.; CHRISTOV, L. H. S. (Org.). O coordenador pedagógico e a formação docente. 8 ed. São Paulo: Edições Loyola, 2007, cp. 1, 9$15 \mathrm{p}$.

GEGLIO, P. C. O papel do coordenador pedagógico na formação do professor em serviço. In: PLACCO, V. M. N. S.; ALMEIDA, L. R. O coordenador pedagógico e o cotidiano da escola. 3 ed. São Paulo, Edições Loyola, 2005, cp.9, 113-120p.

LIBANEO, José C. Organização e gestão da escola: teoria e prática. 5 ed. Revista e ampliada. Goiania: Alternativa, 2008.

LUCK, H. Ação integrada: administração, supervisão e orientação educacional. 25. ed. Petrópolis, RJ: Vozes, 2007.

MEDINA, A. S. Supervisão escolar: da ação exercida à ação repensada. Porto Alegre, Edipucrs, 1995.

PLACCO, V. M. N. de S.; ALMEIDA, L. R. de. O coordenador pedagógico e o cotidiano da escola (Orgs.). São Paulo: Edições Loyola, 2003.

SILVA, C. N. Atuação do coordenador pedagógico nas escolas públicas municipais de Brejões/BA. Trabalho de Conclusão de Curso - Universidade Federal do Recôncavo da Bahia. Amargosa, 2016.

SILVA, N.; SILVA, C. N. Dimensões da Qualidade da Formação de Professores nas Bases Legais Brasileiras. In: GARCIA, R. P. M. Educação como princípio para a Sustentabilidade: políticas, saberes e experiências formativas. Cruz das Almas. UFRB, 2016.

VASCONCELOS, C. dos S. Coordenação do trabalho pedagógico: do projeto político-pedagógico ao cotidiano da sala de aula. São Paulo: Libertad Editora, 2006.

\section{Como referenciar este artigo}

LUCAS, Giseli S.; MONTEIRO, Maria Iolanda. Planejamento em escolas públicas brasileiras na perspectiva de uma gestão escolar interdependente. Revista on line de Política e Gestão Educacional, Araraquara, v.21, n.3, p. 1405-1422, set./dez. 2017. ISSN: 1519-9029.

Submetido em: 14/07/2017

Aprovado em: 26/12/2017 